\title{
Treatment Effects in Strategic Management: With an Application to Choosing Early Stage Venture Capital
}

\author{
Jorge Guzman* \\ Columbia Business School \\ and Columbia Data Science Institute
}

September 1, 2021

FEEDBACK WELCOME.

\begin{abstract}
This paper uses the Rubin Causal Model to formalize the treatment effects of a firm choice on its performance. Building from Porter, a firm choice can shape profitability through both strategy and operational effectiveness, but they are distinct in how they do so. The strategic treatment effect is the benefit that is predictable from a firm's characteristics (i.e., resources) and their joint configuration. The strategic determinant function is a mapping of resources to treatment effects, and the role of resource interactions in it determines the importance of coherence for a strategy. Under unconfoundedness, the strategic treatment effect, strategic determinant function, and coherence can be estimated in high-dimensional observational data using machine learning. I present an application estimating the gains from choosing venture capital as early stage financing versus other forms of capital. The results highlight the advantage of considering strategic benefits in this choice. For equity outcomes, there is no average treatment effect of early stage $\mathrm{VC}$, but there is significant heterogeneity: some entrepreneurs can benefit substantially from raising early stage VC, while others be negatively affected. This heterogeneity is predictable from founder, industry and location characteristics. The estimated role of coherence in this choice is moderate. The formalizations in this paper also show that several additional assumptions are required when assessing strategic benefits compared to the usual causal inference. $\mathrm{R}$ code to replicate these functions will be included.
\end{abstract}

*I am thankful to participants in the Columbia Business School Strategy Crackle, and to Bo Cowgill, Jean Oh, Bruce Kogut, Stephan Meier, Ananya Sen, and Dan Wang for helpful comments. All errors or omissions are my own. Contact. Uris Hall, 711. Columbia University. Broadway \& 116th. New York, NY. 10025. jorge.guzman@columbia.edu 


\section{Introduction}

Strategic management is the study of how strategies (combinations of firm choices and resources) can allow a company to attain and sustain competitive advantage ${ }^{1}$ within a competitive economy (Porter, 1996; Teece et al., 1997). Its applications constitute one of the key areas of study in business schools, and CEOs state it is some of the most important knowledge for the management of their business. ${ }^{2}$ The organizing insight of strategic management (also called 'strategy') is that competitive advantage can only be sustained when the profitable choices a firm takes are hard to replicate by competitors. This can be due to differences in prior investments, underlying assets and resources, regulation, or differences in the logic of the firm. In the now classic article by Porter 'What is strategy?'(Porter, 1996), he further emphasizes that only those choices with ample heterogeneity in their benefit across firms are strategic, while choices that benefit most firms equally are instead 'operational effectiveness', and not a source of sustained competitive advantage. In summary, strategic management studies firm choices with heterogeneous benefits to understand how they uniquely aid specific firms, and the underlying characteristics of firms that predictably determine such benefits.

This focus on heterogeneity - and even on outliers - rather than average treatment effects creates a fundamentally different set of statistical objects for strategic management compared to economic policy. Given Porter's definition, the average treatment effect would not be a strategic benefit, since it abstracts away from heterogeneity. What are the right statistical objects of interest in strategy, and how can one think about them in a structured way? While the underlying ideas of strategy have been around for decades, they have yet to be incorporated into a statistical framework that precisely explains its parameters of interest. Addressing this gap is the purpose of the present paper.

In this paper, I characterize the main strategy treatment effects by implementing the Rubin Causal Model (RCM) (Imbens and Rubin, 2015) within the tenets of strategy, and

\footnotetext{
${ }^{1}$ Competitive advantage is loosely defined as the expected value of future profits accounting for the cost of capital(Porter, 1980).

${ }^{2}$ For example, in a survey of superior CEOs by McKinsey \& Co. 'setting the strategy' was highlighted as the most important skill of a CEO (Dewar et al., 2019).
} 
include an application of these for one question of strategic importance for entrepreneurs: whether to use venture capital during early stage financing. Taking advantage of the distinction between operational effectiveness and strategic choices of Porter, the approach separates treatment effects of a strategy into an average treatment effect and a strategic treatment effect (STE). The STE is the benefit of a firm choice to firm performance that is predictable from the firm's underlying resources, ${ }^{3}$ but independent of the average benefits of the choice. This clarifies how, even though strategic management and economics overlap strongly on their interest in firm profitability, the objects of study are different. The strategic treatment effect is independent of the average treatment effect, and would not be identified when focusing purely on the average change in performance from a random variation, including experiments.

The paper then presents the necessary assumptions for identification of the strategic treatment effect. Under the assumption that principal-agent problems are uncorrelated to the firm benefit of a strategy, the STE can be defined as the treatment effect for a firm at its given propensity of choosing a strategy. I use this measure to define two functions. The first is the strategic determinant function, representing how do underlying firm resources predict strategic treatment effects. The second focuses on assessing a key parameter in strategic management, strategic coherence. This parameter reflects the fact that the benefits of a strategic choice may not vary due to specific firm characteristics alone, but how they present themselves as a bundle.

Next, the paper introduces an approach to estimate these parameters. Doing so requires also assuming unconfoundedness - selection on observables. The unconfoundedness assumption is more likely to be valid when using high-dimensional datasets that include a substantial number of observables to control for selection. Empirically, this implies estimating strategic treatment effects may often only be feasible under large datasets with machine learning.

In the final section of the paper, I implement this approach to estimate the benefits

\footnotetext{
${ }^{3}$ Resources are a loose term embodying all firm characteristics, including "all assets, capabilities, organizational processes, firm attributes, information, knowledge, etc, controlled by a firm." (Barney, 1991)
} 
of receiving early stage venture capital financing - a type of financing where financiers actively engage on firm management and oversight - versus other forms of early stage financing. This choice represents a key strategic choice for startups of consequential importance. The results focus on two different outcomes: a long-term measure of success - achieving an equity sale event (IPO or acquisition) - and a short-term proxy for potential successreceiving future fundraising in a series B financing event. The results evidence heterogeneity at every level, validating the value of the approach in this paper. For equity outcomes, while the average treatment effect in a doubly robust estimator is zero, the strategic treatment effect has ample variation, including values that are highly positive and negative. There is also negative selection into venture capital: the characteristics that predict a high probability of receiving venture capital are not the same as those that predict a high benefit from getting it. Finally, there is a moderate value of coherence in this strategy, introducing interactions in the model increases the total variation explained by $17 \%$. For series $\mathrm{B}$, the estimates are related but different. In particular, the benefit of venture capital on raising series $\mathrm{B}$ is almost always positive, and there is a meaningful region with estimated negative treatment effects on equity outcomes but positive estimates on series B financing. From a managerial perspective, the benefits of considering this heterogeneity in treatment effects, and their conceptualization as strategic choices to take, appear significant.

The approach of this paper has two limitations. The first limitation is that, in implementing the RCM, it was necessary to maintain the common assumption of no interference (also called stable unit treatment value add, or SUTVA) to allow expectations to be valid. This assumption implies that the value of taking a strategic choice for a firm is not affected by whether and when other firms have taken such choice. This assumption is universally applied to analyses of causal inference, but appears particularly difficult to apply when considering the interdependence of strategies. While the application presented in this paper (small firms making private choices), may approximate SUTVA reasonably well, strategies taken under oligopoly could be more complex. The second limitation is that the framework introduced focuses on a simple binary choice and its impact on performance, but strategic choices can be continuous, include multinomial choices from a menu of possibilities, or could require choosing a bundle of choices that interact with each other. Devel- 
oping analytical ways to advance causal inference beyond these limitations is an important avenue for future work.

The paper contributes to three areas of research at the intersection of economics, statistics, and strategic management. First, and most importantly, the main contribution of this paper is to incorporate the RCM into a setting of high economic and educational importance that is uniquely focused on the problem of heterogeneity - what choices lead to persistent differences in firm performance. In doing so, it provides a link between two disciplines, economics and strategic management, that are independent but related. While there is substantial work in strategic management recognizing the importance of heterogeneity (Teece et al., 1994; Rumelt et al., 1991a), the description of this work has lacked a clear statistical framework. A key takeaway from the results in this paper is that the differences between the two fields are more substantial than is often appreciated. Building from the usual definitions, the STE is independent of the average treatment effect. The insights in this paper may allow bringing the questions of strategic management and heterogeneous performance further into their study within the framework of economics while providing a clearer distinction of the strengths of each field. Given how important strategy is considered in both business school education and CEO decision making, it appears fundamental to include the process of strategy into economics to learn about the drivers of firm performance and their role in the economy.

The second contribution of this paper is highlighting a type of heterogeneity that is of fundamental interest in and of itself. Even though there is growing interest in heterogeneity in econometrics (Chernozhukov et al., 2018; Imbens and Rubin, 2015; Wager and Athey, 2018; Chernozhukov and Fernández-Val, 2011), the vast majority of these analyses focus on minimizing policy or medical outcomes conditional on this heterogeneity, such as policy regret. ${ }^{4}$ In this setting, the average treatment effect is usually positive and a reasonable second-best outcome, upon which accounting for heterogeneity just creates an improvement. In contrast, the present paper focuses on managerial action across the heterogeneity itself which is unrelated to this average treatment effect.

\footnotetext{
${ }^{4}$ Policy regret is the difference between an optimal allocation of a policy under perfect knowledge of the heterogeneity on policy response and assignment to treatment (see (Manski, 2004) for more details).
} 
Finally, this paper shows the opportunity and value of using big data and machine learning to understand new causal questions in strategy. The heterogeneity of outcomes in strategy has traditionally made researchers study it through other approaches, such as frameworks, case studies that elucidate key ideas, or theory building that can then be validated with observational data. All of these methods have significant merit and are well complemented by the approach introduced.

The remainder of this paper proceeds as follows. Section 2 provides a quick review of the key concepts of strategic management. Section 3 is the main contribution, incorporating the Rubin Causal Model into strategic management. Section 4 implements this method for the case of seed stage venture capital. Section 5 concludes.

\section{Related Literature: What is Strategic Management?}

Strategic management studies the key choices that managers can take to improve the performance of their firm. This focus on enabling managerial action has often led to the seminal work laying somewhere in the middle between scholarly research and practitioner guidelines. For example, the pioneering conceptualization of strategy in Andrew's The Concept of Corporate Strategy (Andrews, 1971), and the highly influential books Competitive Advantage (Porter, 1980) and Commitment: the Dynamic of Strategy (Ghemawat, 1991), are all books at the intersection of research and practice, allowing large portions of the book to focus on frameworks - such as Porter's Five Forces - and how managers can apply them to the range of problems faced by their business. A formal economic model to define strategy was not developed until Van den Steen (2017). Van den Steen uses an economic model to show how a small set of key choices, which in themselves are interdependent and partially non-reversible, can define a large portion of the follow-on path of the firm. The goal of a manager in formulating strategy is to design these key choices in a way that orients the firm towards sustainable competitive advantage.

Competitive advantage is the expected long-term profitability of a firm within its competitive market. Sustainable competitive advantage is a competitive advantage that can 
withstand competitive forces, including "not only all of [the firm's] current competitors, but also potential competitors poised to enter the industry in a future date" (Barney, 1991). ${ }^{5}$

To create sustainable competitive advantage, strategy focuses on choices that have heterogeneous benefits and therefore may benefit a focal firm but not others. This description is best laid out in Porter (1996). Rather than considering the importance of a managerial choice for firm organization (as in Van den Steen, 2017), Porter considers the nature of choice itself, to ask: if strategy is about firm choices, are all choices therefore strategic? He concludes they are not. There is a second type of firm choice closely tied to performance, operational effectiveness. Porter states:

Operational effectiveness and strategy are both essential to superior performance. [...] But they work in very different ways. A company can outperform its rivals only if it can establish a difference it can preserve. [...] Operational effectiveness (OE) means performing similar activities better than rivals perform them. Operational effectiveness includes but is not limited to efficiency. [...] In contrast [strategy] means performing different activities from rivals' or performing similar activities in different ways. (Porter, 1996) [Italics in original]

Why would one company benefit from a strategic choice while another one would not, even in the same industry? The most common answer to this question comes through the theory of the resource-based view of the firm (Barney, 1991). In this view, firms are best described as collections of resources, a loosely defined term that captures "all assets, capabilities, organizational processes, firm attributes, information, knowledge, etc, controlled by a firm" (Barney, 1991). It is the ownership of these resources, and how they complement specific strategic choices, that allow a firm to implement value-enhancing positions that can be profitable even in the face of potential competition. When resources that complement a strategy are both hard to substitute and hard to get, they allow individual companies to increase value in a way that is difficult to copy by competitors. ${ }^{6}$

Finally, strategy considers how these choices work together. The strategic benefits of a choice are not simply the relationship between the choice and individual resources, but also consider how these resources come as a bundle. Strategic management calls the

\footnotetext{
${ }^{5}$ This definition is admittedly slightly tautological. Since competitive advantage is already considering long-term profitability, it presumably also considers how sustainable any advantage is.

${ }^{6}$ Barney proposes to assess these resources under a VRIN framework - strategic resources should be valuable, rare, imperfectly inimitable, and non-substitutable.
} 
importance of resource complementarity strategic coherence. In an influential argument, Teece et al. (1994) argue that it is the organization of multiple components together (rather than any one on its own) in a coherent picture that leads to specific value creation and value capture propositions. Strategic coherence is therefore a key determinant on the heterogeneous benefits of strategies (Teece et al., 1994; Gans et al., forthcoming).

\section{Strategic Management Inference under the Rubin Causal Model}

To define strategic management statistically, I embed a strategic choice within the Rubin Causal Model (RCM) (Rubin, 1974; Imbens and Rubin, 2015). The RCM, also called potential outcomes, is a general purpose framework for understanding the differences in outcomes under an observed world, and a counterfactual world that is not observed. I focus on a simple binary strategic choice and the way it shapes firm performance. This section begins by describing the key definitions of strategic management under the RCM, and the strategic treatment effect. It then includes several objects of strategic study through the STE, such as the propensity to take a strategy, the strategic determinant function, and the role of strategic coherence. Finally, it considers the possibility of estimating these effects under unconfoundedness in high-dimensional data. The analysis imposes numerous assumptions on functional forms and choice determinants which, even though implicit in most strategy research, appear to be more than usual for causal inference papers. Showing robustness to excluding some of these assumptions could be a rich avenue for future work.

\subsection{Setup}

There is a population of firms indexed by $i$ who are considering a binary strategic choice, $S_{i} \in\{0,1\}$. The firms are fully characterized by a vector of resources $X_{i}$, possibly highdimensional. These resources include the firm's underlying assets, capabilities, and anything else that may shape the profitability of the choice. Each firm has a firm-specific profit function $Y_{i}(\cdot)$, where $Y_{i}(1)$ is the profit of a firm if the choice is taken, and $Y_{i}(0)$ if 
not.

The firm benefit from the strategy is $\Delta_{i}$.

$$
\Delta_{i}=Y_{i}(1)-Y_{i}(0)
$$

This treatment effect can be separated into three components. There is an operational efficiency benefit, this is a benefit that is captured by all firms. There is also a strategic benefit, a benefit that is captured only by some due to a relationship between the choice $S_{i}$ and the firm's underlying resources $X_{i}$. Finally, there is a mean-zero idiosyncratic component $\epsilon_{i}$ that is a result of randomness that will occur after the strategy is taken. Note that, because $\epsilon_{i}$ is incurred after the choice is taken, it is fully independent of $\Delta_{i}$ or selection into treatment. ${ }^{7}$

Assumption 1 (Separability) For the treatment effect $\Delta_{i}$, the operational benefit, the strategic benefit, and the random component are additively separable.

This assumption is standard and is implicit in most definitions of strategy that separate these two. However, a key distinction between the Porter definition and the one in this paper is that Porter posits choices as dichotomous between categories - a specific choice can influence either operational excellence or strategy. Therefore, this is a more general definition allowing a managerial choice to include both, an operational benefit and a strategic benefit.

The benefit of a strategy is therefore three terms.

$$
\Delta_{i}=\text { operational effectiveness of } S_{i}+\text { strategic benefit of } S_{i}+\epsilon_{i}
$$

We next formalize the definitions and functional forms of these terms.

Definition 1 (Operational Effectiveness) The operational expected effectiveness benefit of a strategic choice is defined by a function $g\left(S_{i}\right)$. The value of $g\left(S_{i}\right)$ is independent of the

\footnotetext{
${ }^{7}$ This represents a different assumption than the usual econometric setup, which usually considers $\epsilon_{i}$ as noise and measurement error.
} 
resources that a firm implementing it has.

$$
g\left(S_{i}\right) \Perp X_{i}
$$

This assumption is a formalization of the definition in Porter (1996), which states that operational effectiveness benefits are available to all firms. Therefore this implies they should be available independently of a firm's underlying resources $X_{i}$. Furthermore, because $S_{i}$ is binary in our case, this function can be reduced to a single parameter $\beta$ :

$$
g\left(S_{i}\right)=\beta S_{i}
$$

Definition 2 (Strategic Benefit) The expected strategic benefit of a choice is a function $f\left(S_{i}, X_{i}\right)$, which depends directly on the resources characterizing the firm that implements it.

This assumption is a natural formalization of the resource-based view of the firm (Barney, 1991), which considers the heterogeneity of strategic firms as driven by underlying resources and the ownership (or access) to them.

The treatment effect is thus defined as

$$
\Delta_{i}=\underbrace{\beta S_{i}}_{\text {operational effectiveness }}+\underbrace{f\left(S_{i}, X_{i}\right)}_{\text {strategic benefit }}+\underbrace{\epsilon_{i}}_{\text {randomness }}
$$

We can now consider a preliminary lemma on the expected value of strategic benefits to firms.

Lemma 1 Under definitions (1) and (2) the strategic benefit of a choice is zero for a population.

$$
E\left[f\left(S_{i}, X_{i}\right) \mid S_{i}=1\right]=0
$$

Proof. The proof is by negation logic. Assume $E\left[f\left(S_{i}, X_{i}\right) \mid S_{i}=1\right]=k>0$. Then, this benefit is part of an additional expected benefit available to all firms. However, by definition (1) all generalized benefits must be operational effectiveness and hence included in 
$\beta S_{i}$. Therefore this benefit is not a strategic benefit and $E\left[f\left(S_{i}, X_{i}\right) \mid S_{i}=1\right]$ should be 0 .

Lemma 2 The strategic benefit of a choice is independent of its operational excellence benefit.

$$
E\left[f\left(S_{i}, X_{i}\right)\right] \Perp \beta
$$

Proof. Under Lemma $1 E\left[f\left(S_{i}, X_{i}\right)\right]=0$ always, and therefore independent of $\beta$.

Together, these two lemmas begin to show the importance of studying causal inference in the context of strategic management, and how it leads to unique objects of interest. The next section focuses more clearly on these treatment effects.

\subsection{Treatment Effects}

\subsubsection{Average Treatment Effect and Average Treatment Effect on the Treated}

Now, consider how the two treatment effects of most common interest under RCM, the average treatment effect (ATE) and the average treatment effect on the treated (ATT), map to the setup above. The ATE is the expected change in the outcome of a firm after a choice is taken.

$$
A T E=E\left[\Delta_{i}\right]
$$

The ATT is the expected change for those who take this choice.

$$
A T T=E\left[\Delta_{i} \mid S_{i}=1\right]
$$

Mapping these to the framework of equation (5) we can observe that these two quantities of interest reflect different portions of the returns to strategic choices. Consider the ATE first.

Proposition 1 (ATE is Operational Excellence) The average treatment effect of a business strategy is the operational excellence benefit $\beta$. 


$$
A T E=\beta
$$

Proof. If $E\left[\epsilon_{i}\right]=0$ and, $E\left[f\left(S_{i}, X_{i}\right)\right]=0$ by Lemma 1 . Then, $E\left[\Delta_{i}\right]=E\left[\beta S_{i}\right]=\beta$.

Corollary 1 The ATE is independent of the strategic benefits of a choice.

Proposition 1 and Corollary 1 represent the first important results in this paper: the ATE does not reflect any piece of the strategic value of a choice of a firm. This follows quite naturally from the definition of business strategies as heterogeneous benefits that are unique to each company and dependent on its characteristics. However, it represents a fundamental difference in the object of statistical study. Conceptually, because random assignment is not strategic, then it would not be able to capture the strategic benefit of a choice. Moving to identification strategies, this also implies that the role of pure random assignment may not inform much about strategy. ${ }^{8}$

Corollary 2 The strategic benefits of a strategy are not identified by estimates of the average treatment effect of an experiment.

We next proceed to consider the average treatment effect on the treated (ATT). We can define the ATT under the present framework as

$$
A T T=\beta+E\left[f\left(S_{i}, X_{i}\right) \mid S_{i}=1\right]
$$

This is the benefit of a certain strategy only among those that choose to take it. However, this value is a mix of the operational and strategic benefits of a certain choice. If the operational benefit is also positive, and the choice of treatment has a selection mechanism that is correlated with treatment, then the ATT will be higher than the STE, due to both selection and bias added from the ATE.

Lemma 3 If a strategic choice has an operational benefit, the average treatment effect on

\footnotetext{
${ }^{8} \mathrm{~A}$ natural question to ask at this point is whether the strategic treatment effect is any different from a local average treatment effect. While the full treatment effect of a strategy can be considered a local average treatment for a firm vs its neighbors with similar resources $X_{i}$, the conceptual separation between the operational and strategic piece of this local average treatment effect is what puts the analysis directly into strategic management, and enables some additional ideas to study it.
} 
the treated over claims the strategic benefits of a strategy.

Proof. The intuition is simple. Because the comparisons between treated and non-treated firms will include an operational benefit, then the strategic benefit would necessarily have to be smaller.

\subsubsection{The Strategic Treatment Effect}

The next step is to define the treatment effects that are characterized by the definitions of strategic management. We can define the strategic treatment effect (STE), $\Delta_{i}^{s}$, as the benefit of a choice, net of any operational effeciency benefits.

$$
\Delta_{i}^{s}=\Delta_{i}-A T E=f\left(S_{i}=1, X_{i}\right)-f\left(S_{i}=0, X_{i}\right)
$$

The goal of strategy research is to understand $\Delta_{i}^{s}$ and its determinants. Several elements of this measure may be of managerial interest. For example, managers could study the distribution of $\Delta_{i}^{s}$ in general. Understanding how many firms benefit from an individual strategic choice, or how skewed the tails are, allows managers to understand the potential uniqueness and defensibility of a strategy, and consequently its potential for value creation. As well, managers would like to develop an assessment of where they are in the distribution of $\Delta_{i}^{s}$-i.e. what would be the benefit of this choice for their firm. Finally, managers would benefit from understanding more systematically what firm resources $X_{i}$ better determine variation in this choice.

To understand each of these questions, it is necessary to impose an assignment mechanism into treatment (Imbens and Rubin, 2015). The next section considers the process of selection into a strategic choice to more clearly characterize the returns to business strategies. 


\subsection{Selection into a Strategy and the Strategic Determinant Func- tion}

\subsubsection{Propensity to Take a Strategic Choice}

Following the standard literature, the propensity score $\rho_{i}$ is defined as the probability that a specific firm chooses to take a certain strategy. Two assumptions are necessary.

Assumption 2 (Rational Selection) Firms select into a strategic choice in part due to the benefits they foreshadow of this choice for their performance.

$$
\frac{\partial \rho_{i}}{\partial \Delta_{i}^{s}}>0
$$

This assumption is natural to strategic management since the development of strategy represents the intentional choices of managers to improve the outcomes of their own company. It also allows mapping the underlying STE to the propensity to take a choice, and therefore will simplify inference through the use of the propensity score.

The process of selection is not deterministic and may include a series of other random elements that also shape the choice to take a strategy, such as bounded rationality and the saliency of a choice (Simon, 1986), fads in management choices (Abrahamson, 1996), CEO effects and beliefs (Bennedsen et al., 2020), or founder identity (Gans et al., forthcoming). To incorporate these, we also include an idiosyncratic component $\mu_{i}$. Since these components are not included in the firm resources $X_{i}$, maintaining unconfoundedness requires assuming that selection into a strategy is not influenced by $\mu_{i}$.

Assumption 3 (Uncorrelated noise) The additional parameters that influence selection into strategic choices are uncorrelated with the choice's strategic treatment effect.

$$
E\left[\mu_{i} \Delta_{i}^{s}\right]=0
$$

We can now define the propensity score. Considering, without loss of generality, a strategy that takes no cost to take: 


$$
\begin{gathered}
\rho_{i}=P\left(S_{i}=1\right) \\
S_{i}=1\left[E\left[\Delta_{i}\right]+\mu_{i}>0\right]=1\left[\beta+E\left[\Delta_{i}^{s}\right]+\mu_{i}>0\right]
\end{gathered}
$$

Taking advantage of the vector of resources $X_{i}$, and the unconfoundedness assumption, the propensity score can be estimated as a relationship of these resources to the probability of taking a strategy through some function $h$.

$$
\rho_{i}=h\left(X_{i}\right)
$$

\subsubsection{Definition of Treatment Effects using the Propensity Score}

We now use the propensity score to better characterize the strategic treatment effect for each firm, $\Delta_{i}^{s}$, as the benefit of treatment at a specific propensity score minus the ATE. ${ }^{9}$ For a firm with resources $X^{*}$,

$$
\Delta_{i}^{s}\left(\rho^{*}\right)=E\left[\Delta_{i} \mid \rho_{i}=\rho^{*}\right]-A T E, \rho^{*}=h\left(X^{*}\right)
$$

This definition allows us to consider the individual benefits a strategy has for each firm. Since the propensity score fully indexes the perceived benefits of different strategies for firms (Rosenbaum and Rubin, 1983), then, conditional on an adequate estimate of the propensity score, and enough sources of variation on adoption, the strategic treatment effect can be estimated.

\subsubsection{The Strategic Determinant Function}

We can now back out from this problem the question faced by strategic management analysts: who will benefit from a strategy. This is the function $f\left(S_{i}, X_{i}\right)$, which represents the mapping from firm resources to the expected benefit of a strategy. This is defined as the strategic determinant function. This function potentially can take any functional form.

\footnotetext{
${ }^{9}$ It is an established result in causal inference literature that, under unconfoundedness, the propensity score allows to fully characterize the treatment effect (Rosenbaum and Rubin, 1983).
} 
In this paper, I focus on its linear projection. Because strategy requires resources as bundles, any linear definition of the strategic determinant function must include, at least, the linear relationships of each of the resources to strategic benefits, and the role of two-way complementarities among these to account for some level of strategic coherence.

$$
f\left(S_{i}=1, X_{i}\right)=\widehat{\Delta_{i}^{s}\left(\rho_{i}\right)}=\sum_{j}\left(\gamma_{j} x_{i j}+\sum_{k} \sigma_{j k} x_{i j} x_{i k}\right)
$$

where $\gamma_{j}$ is the impact of resource $j$ to strategy $S_{i}$, and $\sigma_{j k}$ represents the complementarity of resources $j$ and $k$ in the success of this strategy. While it may not be possible to estimate all these coefficients in a high-dimensional method, an assumption of sparsity (i.e., that only a few core resources are key to defining $f$ ) may allow estimating the most important ones.

\subsection{How Much Does Coherence Matter}

Finally, I introduce an estimate of the importance of coherence to a strategy by estimating how important it is to include resource complementarities.

Definition 3 The value of coherence in a strategy, $\zeta$, is the improvement in fit between how a strategic treatment effect is explained by a linear model with and without interactions.

Specifically, if we define $f^{\prime}\left(S_{i}, X_{i}\right)$ as the linear model of $X_{i}$,

$$
f^{\prime}\left(S_{i}=1, X_{i}\right)=\widehat{\Delta_{i}^{s}\left(\rho_{i}\right)}=\sum_{j}\left(\gamma_{j} x_{i j}\right)
$$

then $\zeta$ can be estimated by

$$
\zeta=\frac{R_{f}^{2}}{R_{f^{\prime}}^{2}}
$$

where $R_{f}^{2}$ is the out-of-sample $R^{2}$ statistic of the interacted model $f$, and likewise for $R_{f^{\prime}}^{2}$. 


\subsection{Estimation using High-Dimensional Data}

Finally, I impose one additional assumption to allow introducing an estimation approach using high-dimensional data.

Assumption 4 (Sparsity) There is a small number of unknown true resources that determine the relationship of a strategy to performance.

Assuming sparsity allows incorporating the LASSO (Tibshirani, 1996) and double robust models of Belloni et al. (2014) into the paper. Furthermore, it is consistent with most work in strategic management that focuses on the 'key', or most important, drivers of firm success (e.g. Van den Steen, 2017).

\section{Empirical Setting: Early Stage Venture Capital}

\subsection{Overview}

As the final section in this paper, I implement these ideas to study a specific strategic choice for startups: whether to fulfill their early stage financing needs through venture capital compared to other forms of financing. Venture capitalists are professional investors who raise institutional funds to then invest these in high-growth firms. They get involved early in the company management in exchange for control and a meaningful portion of eq-

uity, and realize a gain on their investment when the equity becomes liquid, either through an IPO or the sale of the company. Besides financial capital, they provide managerial advice, oversight, referrals, and replace founders when necessary. This active engagement has come to call venture capital 'smart capital', emphasizing that their benefits go beyond simply money (Lerner, 1995; Sørensen, 2007; Bernstein et al., 2016; Ewens and Marx, 2018). Overall, there is agreement amongst financial economists that there are substantial startup benefits to raising financing through venture capital besides the capital itself.

However, this evidence has largely been developed for later-stage financing rounds. The benefits of venture capital may not be positive for financing occurring at the early stages of the firm. While venture capital has traditionally involved itself in the company at a 
point called a series A, where the focus of the firm is on moving from a core technology into a defined product, there has been a recent shift to invest earlier in the firm lifecycle. These early stage rounds - which can include seed and pre-seed rounds, as well as rounds raised from angel investors, crowdfunding, accelerators, and grants - are fundamentally more exploratory and include many firms that are still developing many, or all, aspects of the core technology. At this point of the pipeline, the ability of venture capitalists to add value may be muted. For example, it would be harder to replace a founder if they have not yet developed the technology they founded the company for. More generally, because the services venture capital provides are usually aimed at achieving market success for well developed high potential technologies (Hellmann and Puri, 2002), its ability to help firms at the earlier stages could be limited.

Furthermore, even if the benefits of early stage venture capital are positive on average, they may not be positive for all firms. The literature of 'entrepreneurship as experimentation' suggests that, while VCs can separate relatively good firms from the rest, they are unable to pick the potential winners in this set (Kerr et al., 2014; Nanda et al., 2020). There is also evidence documenting how VCs are influenced by systematic biases on easily observable demographics, such as gender (Guzman and Kacperczyk, 2019), and there is increasing evidence that venture capitalists may be differentially able to help firms located close to them (Bernstein et al., 2016). The benefit of early stage venture capital may be too heterogeneous for estimates of its average effect to be useful as individual entrepreneurs advance in their strategic decision-making. Understanding how does early stage venture capital helps firms, and which ones, appears to be a valuable avenue to elucidate.

\subsection{Data}

I study this question using data from Crunchbase. Crunchbase is a well known crowdfunded research database for the study of entrepreneurship. It is particularly focused on early stage startups and the early funding rounds of these firms. Crunchbase also tracks the key employees of the companies, the characteristics of these employees, a startup de- 
scription, business categories (a sort of industry), the funding rounds and investment firms involved in the financing events, and startup outcomes such as whether they IPO, are acquired, or close down. I received all Crunchbase data through a data-sharing agreement with the Crunchbase organization in 2019.

The analysis focuses solely on U.S.-based companies that raised an early stage financing round, defined as any round categorized in Crunchbase as 'seed', 'pre-seed', 'angel', 'incubator', 'crowdfunding', or 'grant'. Though the demand from investors for certain startups varies widely, a key assumption is that everybody that has indeed been able to secure a seed round has sufficient demand that they can choose which form to approach. The resulting dataset is 8,511 companies that raise some form of early stage financing round.

I include a large number of startup observables occurring around the time of early stage financing. To do so, I focused solely on the information available in Crunchbase around one year of founding and hence characterizing firms before they raise early stage capital. Data in Crunchbase also states when a record (e.g. a job position) was added so that all records and information that were created more than one year after the founding date of the company can be removed. This allows characterizing all firms around the time of founding based on what has been disclosed disclose at this time, and avoiding biases created if additional information is filled out ex-post for more successful firms.

Using this approach, I develop a series of binary variables related to the industry, location, financing, and the education of founders. The industry variables are indicators for each of the 187 categories for each firm as stated in Crunchbase. The location includes all 50 U.S. states and all cities with at least 100 deals in the data, which are a total of 43 cities. The education variables include the university, where I focus on the 12 most common universities, and the degrees. I create indicators of the specific type of degrees received by three roles, president/CEO, CMO, and CFO/COO. Finally, I include variables on the amount of early stage financing raised. After including a series of two-way interactions the total number of binary observables for each firm is 728 binary variables.

Table 1 presents the summary statistics of the main treatment variables and outcomes. The average early stage round raise is 1.6 million dollars. $19 \%$ of these early stage financ- 
ing rounds include venture capital, while the rest does not. $14 \%$ of the firms have eventually been acquired, and $0.5 \%$ of them IPO.

\subsection{Results}

\subsubsection{Average Treatment Effects}

Table 2 studies the average treatment effects of early stage venture capital before delving into the heterogeneity of this effect. All regressions include fixed effects for the year of startup founding and cluster standard errors by state. Column (1) is a naïve OLS regression of Early Stage $V C$ on equity outcomes. The coefficient is positive and significant, though likely to be biased if there is positive selection into VC financing. Column (2) uses the richness of the data to implement the double LASSO estimator (Belloni et al., 2014) under the assumption that the observables are able to fully account for selection into VC (i.e., uncounfoundedness). The coefficient is now small, negative, and not significant. Columns (3) and (4) replicate the first two columns but focus only on those companies that have raised specifically seed stage financing, rather than other types of early stage financing. The results are almost identical. These results show that controlling only for available observables makes the average benefits of early stage venture capital are now zero. If we expect the coefficient to be biased upward, the fact that this estimate is now zero would suggest that the observables do account reasonably well for selection in this setting.

Columns (5) and (6) look at a different outcome, raising future financing. They consider specifically series B rounds, which are typically rounds focused on 'scaling' a venture once the main product has been developed. The double LASSO coefficient in this case is positive and significant, emphasizing that raising financing from venture capitalists may continue to be helpful in the ability to procure follow-on financing.

In summary, we observe a zero average treatment effect of venture capital financing in equity success within firms that raise early stage financing, compared to other sources of financing. A typical managerial conclusion from this result would be that early stage venture capital is inconsequential, as it does not improve, nor reduce outcomes. However, this 
conclusion could be misguided for any one entrepreneur as there is possible heterogeneity in these treatment effects that may be substantive for startups making early stage VC beneficial for some and harmful for others.

\subsubsection{Selection into Early Stage Venture Capital}

To study the strategic treatment effects, we begin by first understanding the selection into early stage venture capital. To do so, I estimate the propensity to receive VC by using the rich set of observables available in a random forest model that predicts the probability that a startup that raised early stage financing does so through VC. This is the propensity score for treatment. I estimate this propensity score, $\hat{\rho}_{i}$, as the out of sample prediction of the model in a 10-fold cross validation procedure. Figure 1 plots the ROC curve of these out of sample predictions against Gets Early Stage VC. The area under the curve is 0.72, which implies almost half of the variation being accounted for. ${ }^{10}$

Table 3 reports the top features that most predict the receipt of early stage venture capital. The most important feature is the total amount of early stage financing. This potentially represents differences in the depth of capital and highlights that, even though there is overlap in financing rounds between early stage venture capital and other forms, VC tends to be focused on higher early stage rounds. The next series of key features include a mix of city, industry, and education effects. The next two to six most important features are (in order): being a biotechnology company in San Francisco, being a University of California graduate working on Artificial Intelligence, all firms in artificial intelligence, firms in San Francisco in food and beverage, and graduates of Stanford. In short, the list appears varied and to be truly capturing the rich relationships that exist between observables and the estimate of interest. Figure 2 plots the distribution of out of sample predicted values for this model. The estimated values range from 0 to about 0.7 , with ample variation. Overall, the analysis from this random forest model suggests it is capturing

\footnotetext{
${ }^{10}$ It is important to note that the area under the curve is not a test for unconfoundedness. Unconfoundedness implies that we're able to account for all the correlates to the firm potential outcomes (i.e., the expected values), but we still allow other things uncorrelated with these expectations to enter the selection equation, such as founder preferences for specific VCs, the status benefit of raising venture capital, or path dependence in social networks that is uncorrelated with performance.
} 
the richness of the data and the nuanced relationship between firm characteristics and the likelihood of raising venture capital, observing large differences in the predicted probability of choosing venture capital based on these features.

I next consider how outcomes vary across the propensity score in Figures 3 and 4. Figure 3 plots binned scatterplots for several outcome measures. Panel A is the current treatment of study, getting early stage VC. Panels B and C show that the propensity correlates well with follow-on rounds of financing that tend to typically be driven by VCs, such as series $\mathrm{A}$ and series B. Panels D through F report equity outcomes. Panel D shows that the relationship to equity outcomes is noisy and with a negative correlation. This holds as well for acquisitions (panel E); however, not for IPOs (panel F), which reports a flat correlation between IPOs and our propensity score.

\subsubsection{Strategic Treatment Effect}

This section presents the centerpiece of the analysis, estimating the strategic treatment effect. To do so, I estimate two nonparametric local regression models - one for treated and one for non-treated firms - with performance as the dependent variable and $\hat{\rho}_{i}$ as the independent variable. I use the predicted values of this regression as the empirical equivalent

of the potential outcomes $\hat{Y}_{i}(1)$ and $\hat{Y}_{i}(0)$ and consider the estimated treatment effect the difference of these two. This allows an estimated treatment effect of raising venture capital financing for each firm which can be separated into an operational benefit and a strategic treatment effect.

Figure 4 plots the distribution of these treatment effects. The top panels consider the complete treatment effect. Consistent with the importance of focusing beyond the meanthe theme of this paper - the treatment effect of raising early stage VC on equity growth has ample variation, from -0.10 to 0.10 , relative to an outcome mean of 0.14 . The benefits of early stage venture capital, which are zero on average, may be substantially positive or negative for some groups of firms. The treatment effect for raising a series B has a different distribution. It is positive for almost all firms. The bottom panels focus on the strategic treatment effect. The histogram for equity outcomes is almost the same, but it is 
meaningfully shifted for series B. Indeed, there is a large number of firms that continue to see big strategic benefits of raising $\mathrm{VC}$ on series $\mathrm{B}$, while others face substantial strategic costs, up to -0.15. Figure A2 plots a binned scatterplot of both variables. ${ }^{11}$ Overall, it appears the role of heterogeneity in treatment effects is significant. The strategic treatment effect is the difference between the treatment effect and its mean.

\subsubsection{Strategic Determinant Function}

We next consider the systematic characteristics of firms that determine the benefits of a choice. To do so, I run a cross validated LASSO regression of all startup characteristics on the estimated strategic treatment effect and report the twenty most positive and twenty most negative coefficients selected by this regression. These are the characteristics that most predict a negative or positive benefit of getting early stage venture capital.

Table 4 reports the highest and lowest coefficients predicting the STE of Early Stage $V C$ on Equity Growth in a LASSO model. The most positive features are different than the ones selected by the random forest on selection into early stage VC. The top is being a biotechnology company in New York, followed by a social media company in San Francisco. Then there are two industries, Mobile and Advertising Programs, followed by Redwood City, CA. The most negative features are similarly heterogeneous and a mix of city-industry interactions, city-school interactions, and industries themselves. The variable Early Stage Financing Bin, which was the most positive predictor of getting venture capital, has a negative coefficient in this case, evidencing some negative selection: While venture capitalists are more likely to fund larger rounds, they ultimately help more firms that raise smaller ones. Considering magnitudes, the effect of these coefficients is meaningful, with the bottom coefficients representing as much as a $25 \%$ of the mean value of the dependent variable. There is a substantial and systematic heterogeneity in the strategic treatment effect of early stage venture capital on equity outcomes.

Table 5 reports an analogous set of coefficients for raising a series B. Interestingly, the

\footnotetext{
${ }^{11}$ In Figure A2, we observe that there is some correlation between the treatment effect for equity outcomes and series B, but this correlation is far from unity; there is even a large portion of the sample that has a negative treatment effect for equity growth outcomes and a positive treatment effect for series B.
} 
features selected are substantially different from Table 4. For example, while Table 4 emphasizes several features of the health and biotechnology industries, we do not see them as positive features in Table 5. Instead, they are substantially negative. Furthermore, even though there is a high positive average treatment effect of $\mathrm{VC}$ on series $\mathrm{B}$, the strategic effects are generally negative. In some cases, their magnitude is larger than the average treatment effect, suggesting that, in many cases, strategic considerations would dominate operational ones in this choice.

This analysis emphasizes the importance of strategic choices for firms and the difference of the STE from the average treatment effects of a choice. These strategic treatment effects are determined by different observables than those that predict selection into treatment, and also vary depending on firm goals, such as achieving an equity sale or raising a series B. The role of strategy in choosing early stage venture capital appears substantial.

\subsubsection{Coherence}

Finally, the role of coherence is considered in Table 6 by estimating the role of observables in determining the distribution of the strategic benefits (STE) across startups. Here, I compare the amount of variation explained by a LASSO model that includes interactions of variables, to a model that does not include them. Column (1) is the model on equity growth outcomes. The out of sample R-squared for a fully interacted model is 0.22 , while the out of sample R-squared for a non-interacted model is 0.19 . The increase in the Rsquare due to the interactions is therefore $17 \%$. Coherence, the interdependent presence of resources rather than only one by one, increased the ability to understand a strategy by $17 \%$.

We replicate the same analysis in column (2). Here, both R-square are higher. The value of coherence is $29 \%$. The differences between these two measures emphasize how strategy may be different for different goals related to performance (e.g., raising financing or having an equity event). 


\section{Conclusion}

This paper developed the treatment effects of strategic management by incorporating the tenents of this field under the Rubin Causal Model. A key result is that the focus of strategic management on heterogeneity leads to substantially different treatment effects of interest than the usual ones studied in economics. Indeed, when one formalizes one of the mainstream definitions of strategy vs operational efficiency, the strategic treatment effect is independent of the average treatment effect.

The tools developed in this paper are intended to bring economics and strategic management closer as two distinct fields focused on understanding the sources of firm profitability. This is by no means the first effort to do so (e.g. Rotemberg and Saloner, 1994; Rumelt et al., 1991b). However, it is novel in its effort to apply the Rubin Causal Model, which was emerged as the core statistical framework of interest in economics, in introducing new statistical objects of interest, and in its application of machine learning to study these. Future work building on these ideas would help better understand how to consider firm profitability and translate it into strategic advice for managers, and policy insights for policy makers.

\section{References}

Eric Abrahamson. Management fashion. Academy of management review, 21(1):254-285, 1996.

Kenneth Andrews. The Concept of Corporate Strategy. 1971.

Jay Barney. Firm resources and sustained competitive advantage. Journal of management, 17(1):99-120, 1991.

Alexandre Belloni, Victor Chernozhukov, and Christian Hansen. High-dimensional methods and inference on structural and treatment effects. Journal of Economic Perspectives, 28(2):29-50, 2014.

Morten Bennedsen, Francisco Perez-Gonzalez, and Daniel Wolfenzon. Do ceos matter? evidence from hospitalization events. The Journal of Finance, 75(4):1877-1911, 2020. doi: https://doi.org/10.1111/jofi.12897. URL https://onlinelibrary.wiley.com/doi/abs/10.1111/jofi.12897. 
Shai Bernstein, Xavier Giroud, and Richard R Townsend. The impact of venture capital monitoring. The Journal of Finance, 71(4):1591-1622, 2016.

Victor Chernozhukov and Iván Fernández-Val. Inference for extremal conditional quantile models, with an application to market and birthweight risks. The Review of Economic Studies, 78(2):559-589, 2011.

Victor Chernozhukov, Iván Fernández-Val, and Ye Luo. The sorted effects method: discovering heterogeneous effects beyond their averages. Econometrica, 86(6):1911-1938, 2018.

Carolyn Dewar, Martin Hirt, and Scott Keller. The mindset and practices of excellent ceos. McKinsey Quarterly, 2019.

Michael Ewens and Matt Marx. Founder replacement and startup performance. The Review of Financial Studies, 31(4):1532-1565, 2018.

Joshua Gans, Erin Scott, and Scott Stern. Entrepreneurial Strategy. forthcoming.

Pankaj Ghemawat. Commitment. Simon and Schuster, 1991.

Jorge Guzman and Aleksandra Olenka Kacperczyk. Gender gap in entrepreneurship. Research Policy, 48(7):1666-1680, 2019.

Thomas Hellmann and Manju Puri. Venture capital and the professionalization of start-up firms: Empirical evidence. The journal of finance, 57(1):169-197, 2002.

Guido W Imbens and Donald B Rubin. Causal inference in statistics, social, and biomedical sciences. Cambridge University Press, 2015.

William R Kerr, Ramana Nanda, and Matthew Rhodes-Kropf. Entrepreneurship as experimentation. Journal of Economic Perspectives, 28(3):25-48, 2014.

Josh Lerner. Venture capitalists and the oversight of private firms. the Journal of Finance, 50(1):301-318, 1995.

Charles F Manski. Statistical treatment rules for heterogeneous populations. Econometrica, 72(4):1221-1246, 2004.

Ramana Nanda, Sampsa Samila, and Olav Sorenson. The persistent effect of initial success: Evidence from venture capital. Journal of Financial Economics, 137(1):231-248, 2020 .

ME Porter. Competitive strategy: Techniques for analyzing industries and competitors. 1980.

Michael E Porter. What is strategy? Harvard business review, 74(6):61-78, 1996.

Paul R Rosenbaum and Donald B Rubin. The central role of the propensity score in observational studies for causal effects. Biometrika, 70(1):41-55, 1983. 
Julio J Rotemberg and Garth Saloner. Benefits of narrow business strategies. The American Economic Review, pages 1330-1349, 1994.

Donald B Rubin. Estimating causal effects of treatments in randomized and nonrandomized studies. Journal of educational Psychology, 66(5):688, 1974.

Richard P Rumelt, Dan Schendel, and David J Teece. Strategic management and economics. Strategic management journal, 12(S2):5-29, 1991a.

Richard P Rumelt, Dan Schendel, and David J Teece. Strategic management and economics. Strategic management journal, 12(S2):5-29, 1991b.

Herbert A Simon. Rationality in psychology and economics. Journal of Business, pages S209-S224, 1986.

Morten Sørensen. How smart is smart money? a two-sided matching model of venture capital. The Journal of Finance, 62(6):2725-2762, 2007.

David J. Teece, Richard Rumelt, Giovanni Dosi, and Sidney Winter. Understanding corporate coherence: Theory and evidence. Journal of Economic Behavior ES Organization, 23 (1):1 - 30, 1994. ISSN 0167-2681. doi: https://doi.org/10.1016/0167-2681(94)90094-9. URL http://www.sciencedirect.com/science/article/pii/0167268194900949.

David J Teece, Gary Pisano, and Amy Shuen. Dynamic capabilities and strategic management. Strategic management journal, 18(7):509-533, 1997.

Robert Tibshirani. Regression shrinkage and selection via the lasso. Journal of the Royal Statistical Society: Series B (Methodological), 58(1):267-288, 1996.

Eric Van den Steen. A formal theory of strategy. Management Science, 63(8):2616-2636, 2017.

Stefan Wager and Susan Athey. Estimation and inference of heterogeneous treatment effects using random forests. Journal of the American Statistical Association, 113(523): 1228-1242, 2018. 
Figure 1: ROC score distribution for selection model

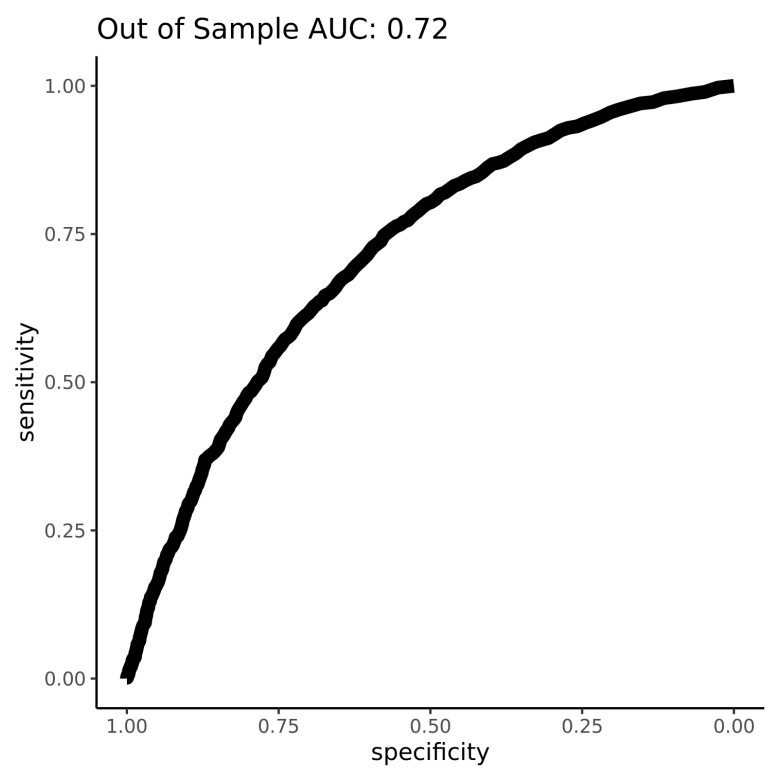

Notes: This figure reports the out of sample ROC score of a random forest model using a set of high dimensional startup observables to predict the probability that a venture capitalist has funded a startup's early stage round, in a sample of startups that received early stage financing.

Figure 2: Histogram of Predictions

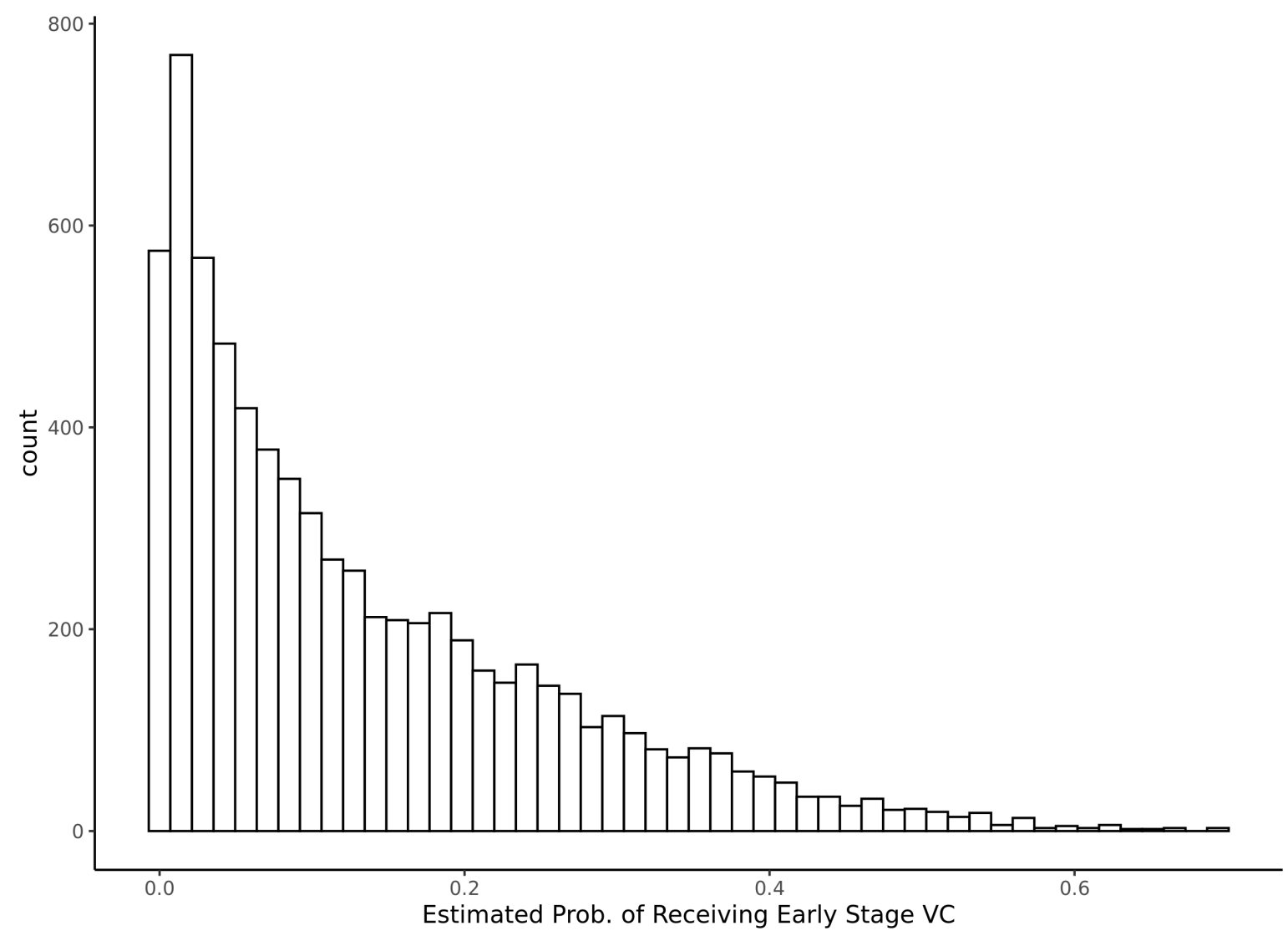

Notes: This figure reports the histogram of out of sample predicted probability of receiving venture capital financing from a random forest model using a set of high dimensional startup observables, in a sample consisting only of startups that received early stage financing. 
Figure 3: Binned scatterplot for outcomes across predicted distribution

A. Early Stage VC

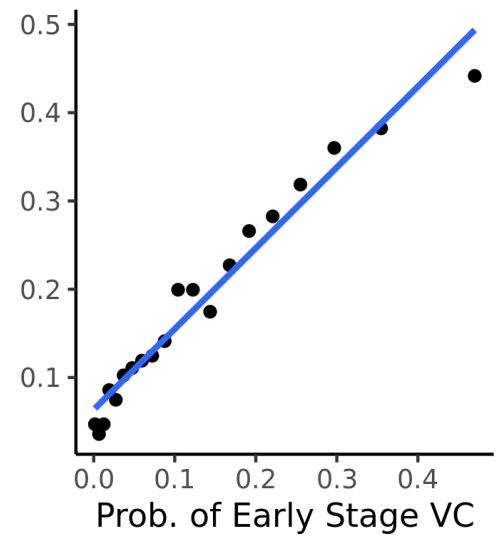

B. Equity Growth

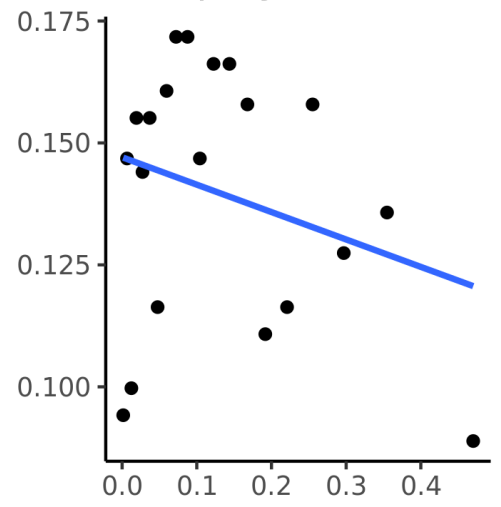

Prob. of Early Stage VC
C. Series A Financing

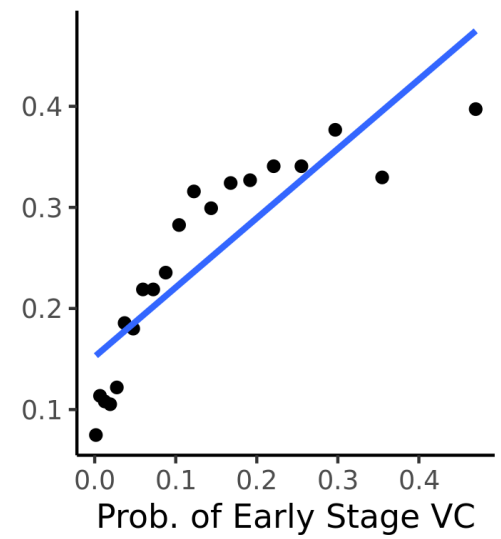

E. Acquired

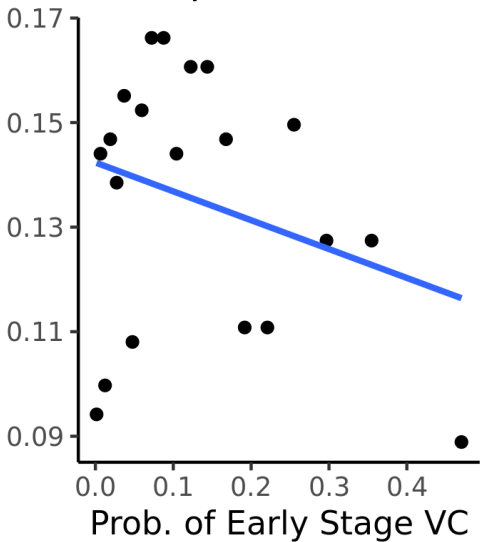

D. Series B Financing

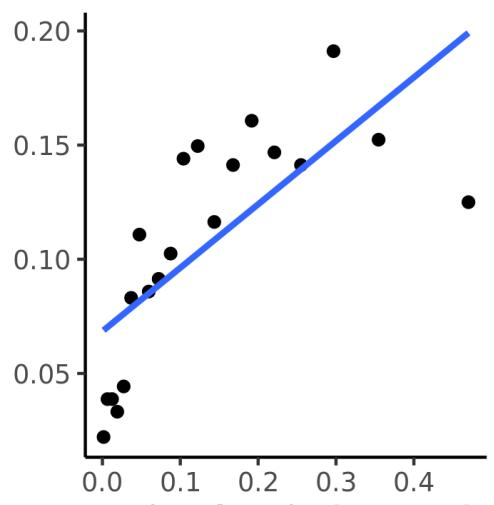

Prob. of Early Stage VC

F. IPO

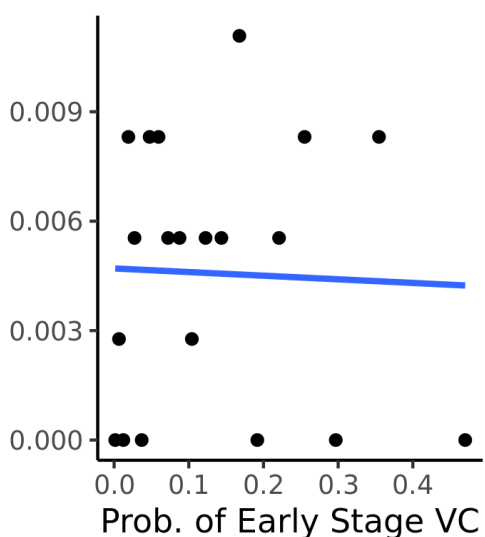

Figure 4: Distribution of treatment effects
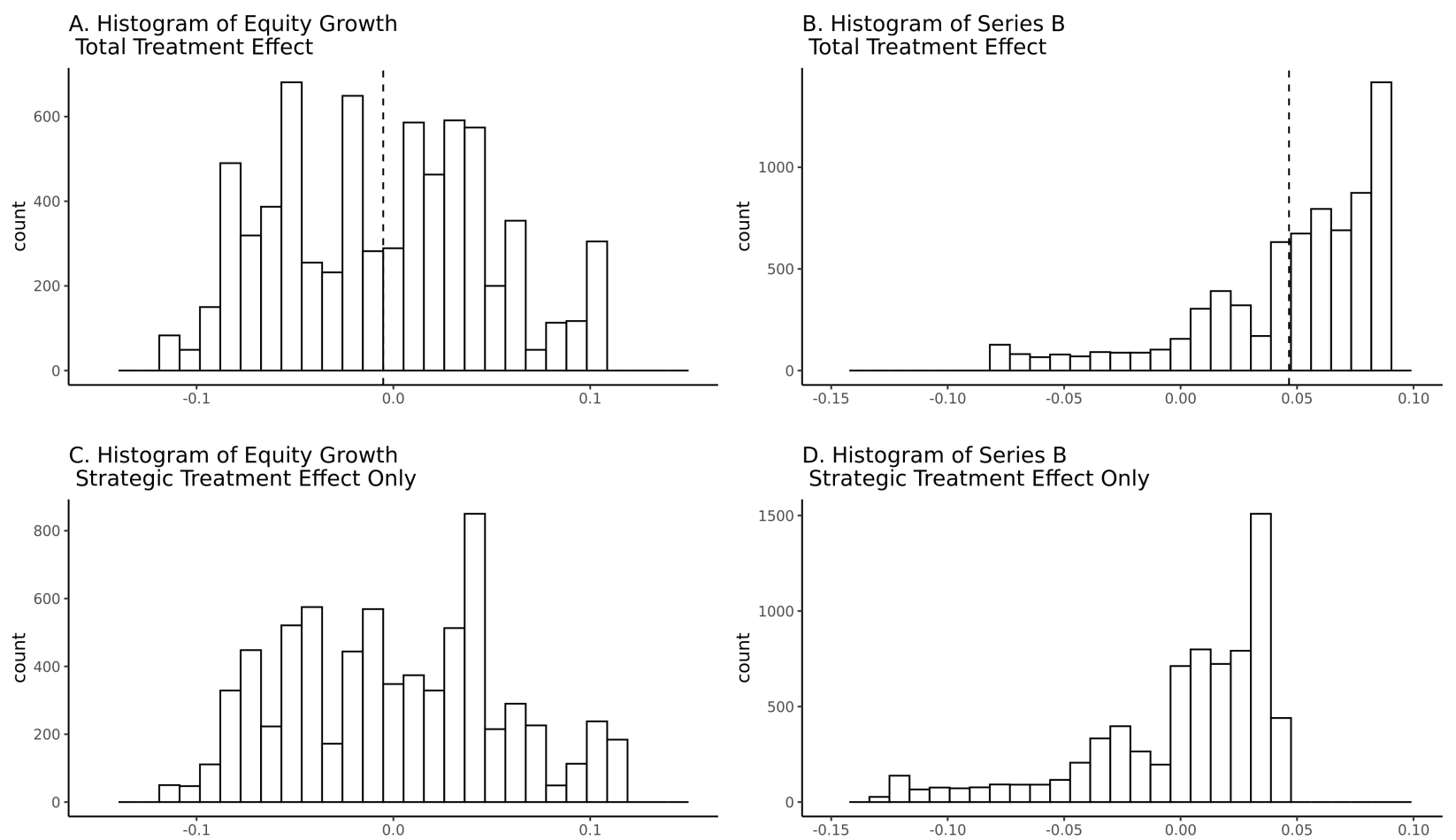
Table 1: Summary Statistics

\begin{tabular}{lcc}
\hline \hline Statistic & Mean & St. Dev. \\
\hline Amount Raised Total & $11,592,973.000$ & $71,123,260.000$ \\
Seed Amount Raised & $1,309,721.000$ & $1,512,657.000$ \\
Angel Funding Amount Raised & $114,929.200$ & $452,395.500$ \\
Early Stage Amount Raised & $1,593,344.000$ & $1,608,507.000$ \\
Series A Amount Raised & $1,923,141.000$ & $4,852,012.000$ \\
Series B Amount Raised & $2,150,582.000$ & $8,973,669.000$ \\
Seed VC & 0.199 & 0.399 \\
Early Stage VC & 0.187 & 0.390 \\
Equity Growth & 0.139 & 0.346 \\
IPO & 0.005 & 0.067 \\
Acquisition & 0.135 & 0.342 \\
\hline
\end{tabular}

Table 2: Double LASSO Estimates of the Main Effect of Early Stage VC Financing

\begin{tabular}{|c|c|c|c|c|c|c|}
\hline & \multicolumn{6}{|c|}{ Dependent variable: } \\
\hline & \multicolumn{4}{|c|}{ Equity Growth } & \multicolumn{2}{|c|}{ Raised Series B } \\
\hline & OLS & Double LASSO & OLS & Double LASSO & OLS & Double LASSO \\
\hline & (1) & (2) & (3) & (4) & (5) & (6) \\
\hline Early Stage VC & $0.026^{*}$ & -0.008 & & & $0.091^{* * *}$ & $0.043^{* * *}$ \\
\hline & $(0.014)$ & $(0.015)$ & & & $(0.016)$ & $(0.015)$ \\
\hline \multirow[t]{2}{*}{ Seed VC } & & & $0.025^{*}$ & -0.008 & & \\
\hline & & & $(0.014)$ & $(0.013)$ & & \\
\hline Observations & 7,219 & 7,219 & 7,219 & 7,219 & 7,219 & 7,219 \\
\hline $\mathrm{R}^{2}$ & 0.095 & 0.133 & 0.095 & 0.134 & 0.052 & 0.113 \\
\hline
\end{tabular}


Table 3: Feature importance of random forest into who gets VC

\begin{tabular}{|c|c|c|}
\hline rank & Variable & Mean Decrease Accuracy \\
\hline 1 & Early Stage Financing Bin & 36.826 \\
\hline 2 & City: SanFrancisco x Industry: Biotechnology & 12.544 \\
\hline 3 & School: Universityof x Industry: ArtificialIntelligence & 9.205 \\
\hline 4 & City: NewYork X Harvard & 8.887 \\
\hline 5 & City: Portland x Industry: EnterpriseSoftware & 8.877 \\
\hline 6 & City: Austin x Industry: MachineLearning & 8.799 \\
\hline 7 & City: Boulder x Industry: Software & 8.730 \\
\hline 9 & City: NewYork x Industry: PredictiveAnalytics & 7.755 \\
\hline 10 & Industry: OpenSource & 7.612 \\
\hline 11 & City: Boston x Industry: FinTech & 7.554 \\
\hline 12 & Industry: MachineLearning & 7.323 \\
\hline 13 & Industry: EdTech & 6.988 \\
\hline 14 & City: Austin x Industry: ArtificialIntelligence & 6.632 \\
\hline 15 & School: Stanford x Industry: Analytics & 6.322 \\
\hline 16 & Industry: 3DTechnology & 6.136 \\
\hline 17 & School: Stanford x Industry: ArtificialIntelligence & 5.845 \\
\hline 18 & State: Michigan & 5.727 \\
\hline 19 & City: MountainView x Industry: ECommerce & 5.705 \\
\hline 20 & City: NewYork X Stanford & 5.573 \\
\hline 21 & School: Harvard & 5.549 \\
\hline 22 & City: SanFrancisco x Industry: Retail & 5.539 \\
\hline 23 & City: SanFrancisco x Industry: HealthDiagnostics & 5.454 \\
\hline 24 & City: Boulder x Industry: SaaS & 5.416 \\
\hline 25 & Industry: ArtificialIntelligence & 5.382 \\
\hline 26 & City: SanFrancisco x Industry: InformationTechnology & 5.226 \\
\hline 27 & School: Stanford & 5.226 \\
\hline 28 & City: Boston X Harvard & 5.042 \\
\hline 30 & City: Atlanta x Industry: InformationTechnology & 4.933 \\
\hline 31 & School: University of California & 4.933 \\
\hline 32 & Industry: Sales Automation & 4.850 \\
\hline 33 & City: SanJose X University of California & 4.829 \\
\hline 34 & School: Stanford x Industry: HealthCare & 4.779 \\
\hline 35 & City: SanFrancisco x Industry: Education & 4.721 \\
\hline 36 & City: Chicago X KelloggSchool & 4.560 \\
\hline 38 & Industry: ComputerVision & 4.460 \\
\hline 39 & School: MIT x Industry: Analytics & 4.378 \\
\hline 40 & City: SanFrancisco x Industry: CloudComputing & 4.335 \\
\hline 41 & City: Austin X Berkeley & 4.299 \\
\hline 42 & City: SanFrancisco x Industry: Robotics & 4.265 \\
\hline 44 & City: NewYork x Industry: VirtualReality & 4.145 \\
\hline
\end{tabular}


Table 4: Strategic Determinant Function: Top Features for Equity Growth Treatment Effect

\begin{tabular}{|c|c|c|c|}
\hline & Variable & Coefficient & Coefficient/ATE \\
\hline \multicolumn{4}{|c|}{ Panel A: Most Positive Features } \\
\hline 1 & City: New York x Industry: Biotechnology & 0.007 & -1.320 \\
\hline 2 & City: San Francisco x Industry: Social Media & 0.007 & -1.280 \\
\hline 3 & Industry: Mobile & 0.003 & -0.600 \\
\hline 4 & Industry: Advertising Platforms & 0.003 & -0.580 \\
\hline 5 & City: Redwood City & 0.002 & -0.330 \\
\hline 6 & Industry: Medical & 0.001 & -0.190 \\
\hline 7 & City: New York x Industry: Android & 0.001 & -0.190 \\
\hline 8 & City: Washington x Industry: Software & 0.001 & -0.190 \\
\hline 9 & School: University of California & -0.0001 & 0.020 \\
\hline 10 & City: New York x Industry: Blockchain & -0.0001 & 0.020 \\
\hline 11 & City: New York x Industry: Subscription Service & -0.0002 & 0.040 \\
\hline 12 & City: San Francisco x Industry: Big Data & -0.0002 & 0.040 \\
\hline 13 & Industry: SaaS & -0.0003 & 0.060 \\
\hline 14 & Industry: Predictive Analytics & -0.0005 & 0.100 \\
\hline 15 & City: San Francisco x Industry: Health Care & -0.0005 & 0.100 \\
\hline 16 & City: San Francisco x Industry: Personalization & -0.0005 & 0.100 \\
\hline 17 & Industry: Human Resources & -0.001 & 0.140 \\
\hline 18 & City: New York x Industry: Hospitality & -0.001 & 0.140 \\
\hline 19 & City: San Francisco x Industry: Retail & -0.001 & 0.160 \\
\hline 20 & City: New York x Industry: Business Intelligence & -0.001 & 0.190 \\
\hline \multicolumn{4}{|c|}{ Panel B: Most Negative Features } \\
\hline 82 & Industry: Cloud Infrastructure & -0.011 & 2.150 \\
\hline 83 & City: San Francisco & -0.011 & 2.170 \\
\hline 84 & Industry: Aerospace & -0.011 & 2.210 \\
\hline 85 & School: Harvard & -0.012 & 2.230 \\
\hline 86 & City: San Francisco x Industry: Cloud Computing & -0.012 & 2.330 \\
\hline 87 & City: Boston x Industry: Fin Tech & -0.012 & 2.350 \\
\hline 88 & City: Chicago X Kellogg School & -0.012 & 2.420 \\
\hline 89 & School: Stanford & -0.012 & 2.420 \\
\hline 90 & City: San Francisco x Industry: Mediaand Entertainment & -0.012 & 2.420 \\
\hline 91 & Industry: Developer Platform & -0.013 & 2.560 \\
\hline 92 & City: New York x Industry: Transportation & -0.013 & 2.600 \\
\hline 93 & City: San Francisco x Industry: Biotechnology & -0.014 & 2.640 \\
\hline 94 & Early Stage Financing Bin & -0.014 & 2.790 \\
\hline 95 & City: Portland x Industry: Enterprise Software & -0.015 & 2.830 \\
\hline 96 & Industry: Open Source & -0.016 & 3.020 \\
\hline 97 & City: San Francisco x Industry: Foodand Beverage & -0.016 & 3.040 \\
\hline 98 & City: San Mateo x Industry: Information Technology & -0.017 & 3.220 \\
\hline 99 & City: New York X Wharton School & -0.017 & 3.370 \\
\hline 100 & Industry: Database & -0.020 & 3.780 \\
\hline 101 & City: Mountain View x Industry: ECommerce & -0.025 & 4.870 \\
\hline 102 & City: Boston x Industry: Health Care & -0.029 & 5.700 \\
\hline
\end{tabular}


Table 5: Strategic Determinant Function: Top Features for Series B Treatment Effect

\begin{tabular}{|c|c|c|c|}
\hline & Variable & Coefficient & Coefficient/ATE \\
\hline \multicolumn{4}{|c|}{ Panel A: Most Positive Features } \\
\hline 1 & City: New York x Industry: Cloud Computing & 0.007 & 0.150 \\
\hline 2 & City: Atlanta X Stanford & 0.005 & 0.100 \\
\hline 3 & City: New York x Industry: Advertising & 0.004 & 0.090 \\
\hline 4 & City: San Francisco x Industry: Social Media & 0.003 & 0.070 \\
\hline 5 & Industry: Mobile & 0.003 & 0.060 \\
\hline 6 & Industry: Retail Technology & 0.002 & 0.050 \\
\hline 7 & City: San Francisco x Industry: Mobile & 0.002 & 0.040 \\
\hline 8 & City: Santa Monica x Industry: Mobile & 0.002 & 0.040 \\
\hline 9 & City: New York x Industry: Digital Media & 0.002 & 0.040 \\
\hline 10 & City: San Francisco x Industry: Finance & 0.0005 & 0.010 \\
\hline 11 & City: Los Angeles x Industry: ECommerce & 0.0003 & 0.010 \\
\hline 12 & Region: Texas & 0 & 0 \\
\hline 13 & City: Palo Alto X INSEAD & 0 & 0 \\
\hline 14 & City: San Francisco x Industry: Location Based Services & 0 & 0 \\
\hline 15 & Industry: Events & -0.0001 & 0 \\
\hline 16 & City: Boston & -0.0001 & 0 \\
\hline 17 & City: San Diego & -0.0001 & 0 \\
\hline 18 & ed Stanford x Industry: Artificial Intelligence & -0.0001 & 0 \\
\hline 19 & School: University of California & -0.0002 & 0 \\
\hline 20 & City: San Francisco x Industry: Hospitality & -0.0002 & 0 \\
\hline \multicolumn{4}{|c|}{ Panel B: Most Negative Features } \\
\hline 214 & City: Boston x Industry: Fin Tech & -0.032 & -0.690 \\
\hline 215 & City: Chicago X Kellogg School & -0.032 & -0.700 \\
\hline 216 & City: Los Angeles X Columbia & -0.032 & -0.700 \\
\hline 217 & City: New York X Stanford & -0.033 & -0.710 \\
\hline 218 & City: Boston X Universityof & -0.033 & -0.720 \\
\hline 219 & City: Boston x Industry: Health Care & -0.033 & -0.720 \\
\hline 220 & City: San Francisco x Industry: Cloud Computing & -0.033 & -0.720 \\
\hline 221 & City: Boulder x Industry: SaaS & -0.035 & -0.750 \\
\hline 222 & City: Austin x Industry: Machine Learning & -0.036 & -0.770 \\
\hline 223 & City: Los Angeles x Industry: Saa S & -0.037 & -0.790 \\
\hline 224 & City: San Jose X University of California & -0.038 & -0.820 \\
\hline 225 & City: New York X Harvard & -0.039 & -0.840 \\
\hline 226 & City: Boulder x Industry: Software & -0.040 & -0.870 \\
\hline 227 & City: New York x Industry: Commercial Real Estate & -0.041 & -0.880 \\
\hline 228 & City: Palo Alto x Industry: Artificial Intelligence & -0.042 & -0.900 \\
\hline 229 & City: San Francisco x Industry: Foodand Beverage & -0.045 & -0.970 \\
\hline 230 & City: San Francisco x Industry: Robotics & -0.045 & -0.970 \\
\hline 231 & City: Austin x Industry: Artificial Intelligence & -0.051 & -1.100 \\
\hline 232 & City: Portland x Industry: Enterprise Software & -0.058 & -1.230 \\
\hline 233 & City: Mountain View x Industry: ECommerce & -0.064 & -1.370 \\
\hline 234 & City: San Francisco x Industry: Biotechnology & -0.084 & -1.790 \\
\hline
\end{tabular}


Table 6: Estimates of the Importance of Coherence

\begin{tabular}{ccc}
\hline \hline Statistic & Equity Growth Model & Series B Model \\
\hline R Square Full Model & 0.223 & 0.490 \\
R Square Non Interacted Model & 0.190 & 0.380 \\
Value of Coherence & 0.172 & 0.291 \\
\hline
\end{tabular}


Appendix 
Figure A1: Histogram of amount raised as early stage fundraising for firms with and without VC
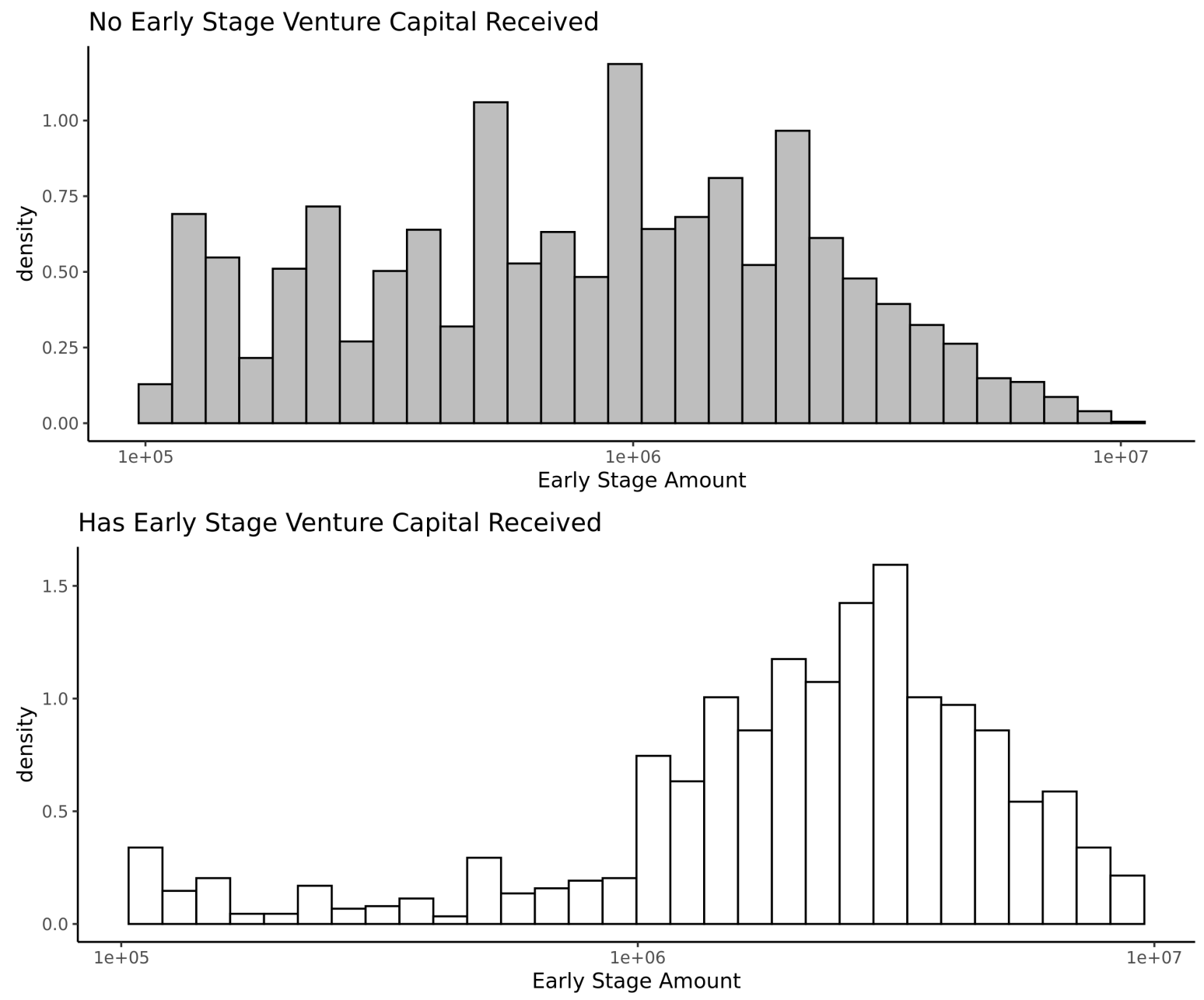
Figure A2: Binned scatterplot treatment effects for equity growth and series B

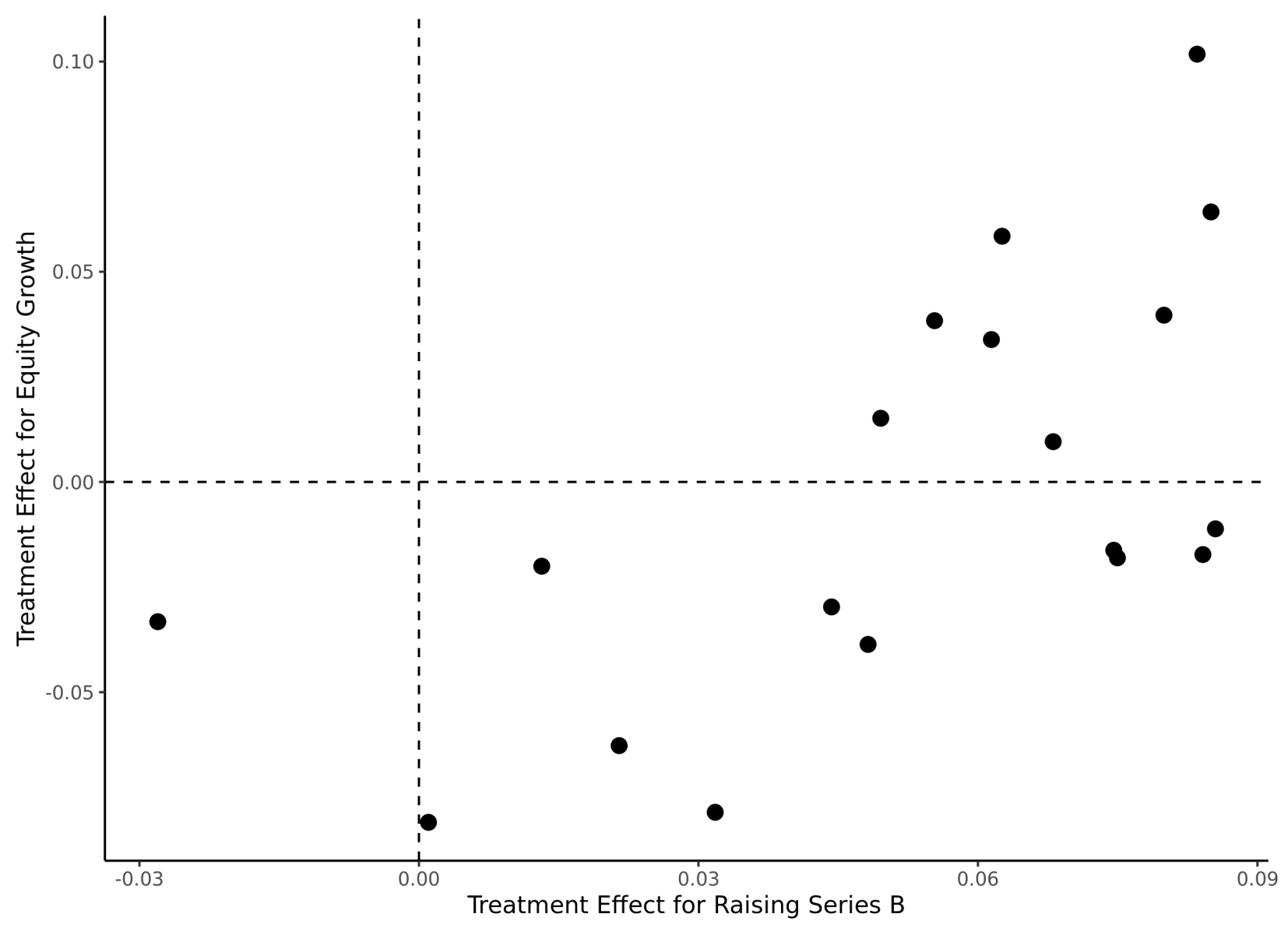

